\title{
Internal Stresses and Structure of Multilayer Coatings on the Basis of $\mathrm{Zr}-\mathrm{Y}-\mathrm{O} / \mathrm{Si}-\mathrm{Al}-\mathrm{N}$
}

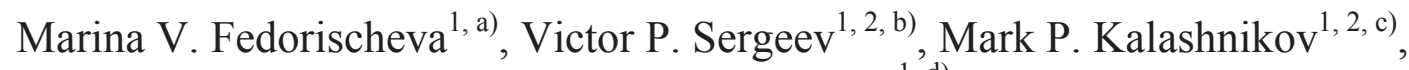 \\ and Andrei V. Voronov ${ }^{1, d)}$ \\ ${ }^{1}$ Institute of Strength Physics and Materials Science SB RAS, Tomsk, 634055, Russia \\ ${ }^{2}$ National Research Tomsk Polytechnic University, Tomsk, 634050, Russia \\ a) Corresponding author: fmw@ispms.tsc.ru \\ b)vserg@mail.tomsknet.ru \\ c) kmp1980@mail.ru \\ d) rets@ispms.tsc.ru
}

\begin{abstract}
X-ray and TEM research of the structure of multilayered coatings consisting of the alternating layers $\mathrm{Si}-\mathrm{Al}-\mathrm{N}$ and $\mathrm{Zr}-\mathrm{Y}-\mathrm{O}$ of equal thickness are carried out. It is shown that the boundaries between different layers are sharp enough, and the chemical composition in each layer is homogeneous. The phase composition of the layers on the basis of $\mathrm{Zr}-\mathrm{Y}-\mathrm{O}$ contains basically nanocrystalline $\mathrm{ZrO}_{2}$ and the layers on the basis of Si-Al-N contain $\mathrm{Si}_{3} \mathrm{~N}_{4}$ amorphous phase. The internal field of stresses is determined by X-ray and TEM analyses. It is established that the crystal lattice curvaturetorsion and the internal elastic stresses depend on the grain cross-section size of the $\mathrm{Zr}-\mathrm{Y}-\mathrm{O}$ layer.
\end{abstract}

Keywords: internal stresses, microstructure, multilayer heat-shielding coatings, curvature-torsion, grain size, magnetron deposition, phase composition

\section{INTRODUCTION}

Internal stress fields play an important role in the formation of yield stress, strain hardening, and especially in crack nucleation. The role of internal field stresses is vital in the defect structure evolution at phase transformations. The field of stresses can be measured by optical and magnetic methods. These methods are integral, and they are used to investigate the areas of a centimeter range. X-ray analysis can measure the stress field (stresses of the first and second kind) in a millimeter area. The diffraction electron microscopy method can measure the local fields of stress in a wide range (from hundreds to a few nanometers) [1].

When the nanocrystalline structures are formed without dislocations, structural states with the high curvaturetorsion of the crystal lattice are characteristic. This material characteristic plays an important role in all types of structural-phase transitions in solids. In the literature, it is well-known that the phase nucleation and martensitic transformations in alloys occur on the deformation defects. The discontinuous decomposition in alloys is related to the local curvature of grain boundaries [1].

Heat-shielding coatings on the basis of $\mathrm{Zr}-\mathrm{Y}-\mathrm{O}$ are applied in the production of gas turbine engines to protect them from heat units: combustion chambers, impellers, blades and nozzle turbines, etc. Nanostructured multilayer coatings are of special interest. They ensure the minimum modulation amplitude of normal and tangent stresses on all the interfaces of the multilayer coatings, which cardinally improves operational characteristics. The intermediate layers consist of the layers bearing mechanical loads. Amplitude stresses, which appear during the thermal cycling in the multilayered coating, relax [2-4].

The paper deals with the results of TEM and X-ray study of the structure-phase state and the crystal lattice curvature-torsion of the elastic stress state in the $\mathrm{Zr}-\mathrm{Y}-\mathrm{O}$ layer in the $\mathrm{N}$ multilayer coatings based on $\mathrm{Zr}-\mathrm{Y}-\mathrm{O} / \mathrm{Si}-$ $\mathrm{Al}-\mathrm{N}$.

International Conference on Physical Mesomechanics of Multilevel Systems 2014

AIP Conf. Proc. 1623, 147-150 (2014); doi: 10.1063/1.4898904

(C) 2014 AIP Publishing LLC 978-0-7354-1260-6/\$30.00 
TABLE 1. Phases, type of crystalline lattices, space groups, crystalline lattice parameters in the $\mathrm{Zr}-\mathrm{Y}-\mathrm{O} / \mathrm{Si}-\mathrm{Al}-\mathrm{N}$ multilayer coatings

\begin{tabular}{cccc}
\hline Phase & Type of Crystalline Lattice & Space group & Crystalline lattice parameters, \\
\hline $\mathrm{ZrO}_{2}$ & Tetragonal & $\mathrm{P} 4_{2} / \mathrm{nmc}$ & $a=5.12, b=5.12, c=5.25$ \\
\hline $\mathrm{ZrO}_{2}$ & Monoclinic & $\mathrm{P} 2_{1} / \mathrm{b}$ & $a=5.3129, b=5.2125, c=5.1471$ \\
\hline $\mathrm{Si}_{3} \mathrm{~N}_{4}$ & Hexagonal & $\mathrm{P} 6_{3} / \mathrm{m}$ & $a=4.065, b=4.065, c=4.906$ \\
\hline $\mathrm{Si}_{3} \mathrm{~N}_{4}$ & Hexagonal & $\mathrm{P}_{1} \mathrm{c}$ & $a=7.475, b=6.727, c=3.732$ \\
\hline $\mathrm{AlN}$ & Hexagonal & $\mathrm{P} 6_{3} \mathrm{mc}$ & $a=3.1114, b=3.1114, c=4.9792$ \\
\hline
\end{tabular}

\section{EXPERIMENTAL}

The deposition of the coating was carried out by means of the KVANT-03MI equipment [5] with two magnetrons using mosaic zirconium-yttrium and aluminum-silicon targets. The surface of the copper substrate measuring $20 \times 30 \mathrm{~mm}$ was polished up to the roughness $R_{\mathrm{a}}=0.16 \mu \mathrm{m}$ before ionic treatment. The magnetron was powered from a pulse source with the frequency of $50 \mathrm{kHz}$. The sample was placed in a chamber on a rotating table, which could be moved in different directions - in front of the ion source for the ion bombardment, and then in front of the magnetron for the coating deposition. The substrate bias potential was $-900 \mathrm{~V}$ at the bombardment of the substrate surface layer and $-100 \mathrm{~V}$ at the coating deposition. The sample temperature during the deposition of coatings was $573 \mathrm{~K}$.

The structural-phase state of the copper substrate surface layers was investigated by X-ray diffraction using the DRON-7 device in the Co- $\mathrm{K}_{\alpha}$ radiation. A fine structure of the multilayer coatings was investigated by transmission electron microscopy (TEM) using the JEM-2100 device. A foil was prepared by the "cross-section" method using the ION SLISER-EM-09100IS installation.

\section{RESULTS AND DISCUSSION}

Table 1 shows the phases which the coatings can contain and the theoretical lattice parameters from JCPDS database. There are two modifications of the $\mathrm{ZrO}_{2}$ phases, two modifications of the $\mathrm{Si}_{3} \mathrm{~N}_{4}$ phases and the $\mathrm{Al}-\mathrm{N}$ phase in these systems.

It is found by X-ray that there are the $\mathrm{ZrO}_{2}$ phases in two different structural modifications in the multilayer coating: tetragonal $(\mathrm{t})$ and monoclinic $(\mathrm{m})$. Other phases are not found in this layer of the coating.

Figure 1 shows the cross-section of $\mathrm{Zr}-\mathrm{Y}-\mathrm{O} / \mathrm{Si}-\mathrm{Al}-\mathrm{N}$ coating. It can be seen that a boundary between the layers of $\mathrm{Si}-\mathrm{Al}-\mathrm{N}$ and $\mathrm{Zr}-\mathrm{Y}-\mathrm{O}$ is sharp enough. The coating consists of the layers possessing different contrasts: light and dark (Fig. 1(a)). As it has been previously shown [1], the layer on the basis of $\mathrm{Zr}-\mathrm{Y}-\mathrm{O}$ has a dark contrast and two modifications of the $\mathrm{ZrO}_{2}$ phase have tetragonal and monoclinic ones. The layer on the basis of the $\mathrm{Si}_{3} \mathrm{~N}_{4}$ phase has a light contrast. It can be seen (Fig. 1) that this layer is in the amorphous state. It is a typical microdiffraction for amorphous materials (Fig. 1(d)).

The grain structure of the coating layer on the basis of $\mathrm{Zr}-\mathrm{Y}-\mathrm{O}$ is columnar. The longitudinal size of the grains of the $\mathrm{ZrO}_{2}$ phase coincides with a growth axis of the coating. A column height is determined by the layer thickness, and the average cross dimension of the grains is less than about $80 \mathrm{~nm}$. The height of the columns depends on the deposition time of the layer and can be adjusted depending on the application. In this particular case, the column height of the coating layer is about $1000 \mathrm{~nm}$ (Fig. 1).

Conventionally, the $\mathrm{ZrO}_{2}$ coating layer can be divided into three parts (Fig. 1): a part of the coating layer, which is adjacent to the bottom of the interface (the interface between the layer of $\mathrm{Si}-\mathrm{Al}-\mathrm{N}$ and $\mathrm{Zr}-\mathrm{Y}-\mathrm{O}$ ); a middle part of the coating layer and a portion of the layer adjacent to the upper interface (between $\mathrm{Zr}-\mathrm{Y}-\mathrm{O}$ and $\mathrm{Si}-\mathrm{Al}-\mathrm{N}$ ). The average cross grain size of the bottom $\mathrm{ZrO}_{2}$ layer in the above parts is 20, 45 and $80 \mathrm{~nm}$ correspondingly which is confirmed by the X-ray data. The size of the coherent scattering area (for nanomaterials it is the grain size [6]) is about $50 \mathrm{~nm}$.

This is the average grain size determined by TEM. The difference in the grain size in the layer on the basis of $\mathrm{Zr}-\mathrm{Y}-\mathrm{O}$ is due to the fact that the layer formation begins from the boundary forming fine grains. Such regularity in the formation of the $\mathrm{Zr}-\mathrm{Y}-\mathrm{O}$ layer is common for all the layers in the multilayer coatings. 

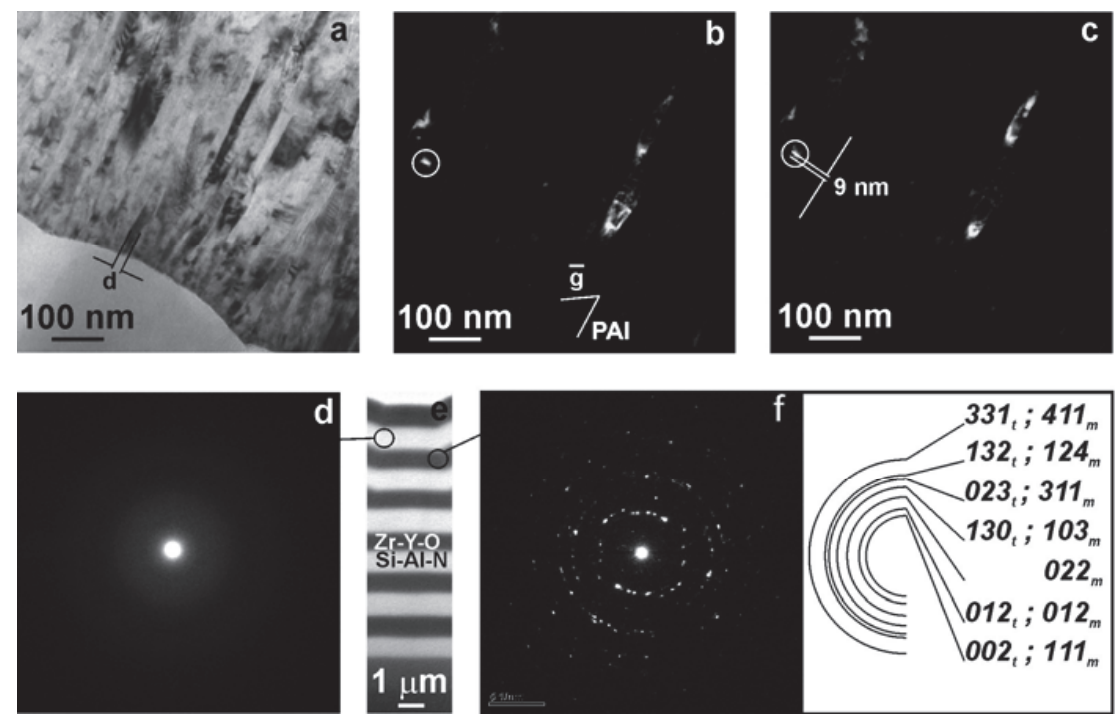

FIGURE 1. TEM image of the multilayer coatings on the basis of $\mathrm{Si}-\mathrm{Al}-\mathrm{N} / \mathrm{Zr}-\mathrm{Y}-\mathrm{O}$, with $1000 \mathrm{~nm}$ in thickness of the separate layers: the bright field image of the multilayer coating cross-section (a), the dark-field showing a shift of extinction contours and goniometer is tilted at the angle of one degree $(b, c)$, the microdiffraction pattern of $\mathrm{Si}-\mathrm{Al}-\mathrm{N}$ coatings in the amorphous state (d),

the boundary of the layers (e), the microdiffraction pattern and the indexing scheme of the layer on the basis of $\mathrm{Zr}-\mathrm{Y}-\mathrm{O}$ (f)

Estimates of the crystal lattice curvature-torsion allow us to value the level of the local internal stresses, which lead to the significant improvement in the mechanical properties of nanomaterials. The internal stress field leads to the appearance of the bending extinction contours in the TEM images. The parameters of the extinction contours can be used to reconstruct the stress field [7]. They are identified by the relative orientation of the extinction contour line and the vector of the current reflection $\bar{g}$ [111]. The authors propose the method for determining the tensor components of the internal stress from the crystalline lattice curvature-torsion [8-10]. The components of the internal stress tensor in both cases allow determining the parameters of the bending extinction contours observed in the electron microscopic images of the material (Fig. 1(b, c)).

Figure 2 shows the distribution of the crystal lattice curvature-torsion and the internal elastic stresses depending on the grain cross-section size in the coating. It can be seen that the dependence of the curvature-torsion as a function of the grain size is strictly rectilinear unlike the internal elastic stresses depending on the grain size. Here the rectilinear part takes place up to the grain size of $30 \mathrm{~nm}$ and then the curve gradually decreases to the value of $1.2 \mathrm{GPa}$.

It is interesting to note, that the internal elastic stresses, measured by X-ray from the broadening of X-ray lines, are two orders lower than the stresses measured by the curvature-torsion of the crystal lattice, and the value is $0.4 \mathrm{GPa}$ as it is shown in [6]. It is known that for bulk materials the local or moment stresses and the tensilecompression stresses (X-ray data) are usually close [11]. As for nanomaterials, the picture is somewhat different. The high curvature-torsion zone of the crystal (the extinction contour shifts a few nanometers as shown in Fig. 1) does not take part in the formation of the diffraction pattern and it is invisible for X-ray [10].

A decrease in the internal elastic stresses is related to the structure of nanocrystalline grains themselves.

It is known [11] that the thickness of the grain boundary can change when the grain size, the grain boundaries, the junction disclination, and the compositional nanomaterial change. At the moment, both the experimental data and the theoretical estimates of the simulation results show that the thickness of the grain boundary regions is in the range of $0.5-1.0 \mathrm{~nm}$. The structure of the grain boundaries, the internal stress field and also the segregation lead to the hardened zone formation near the grain boundaries $[12,13]$.

When the average grain size decreases, the grain boundary fraction of the strengthened part increases and can reach half of the grain size at the micro level. As for the nanocrystals, the strengthened part can cover all the grains as a whole. Schematically, it is well represented by the model of the grain-boundary box [14]. In this case, a portion of the hardened zone near the grains gradually decreases when the grain size increases. This phenomenon leads to decreasing the crystalline lattice curvature-torsion and the internal stresses. 


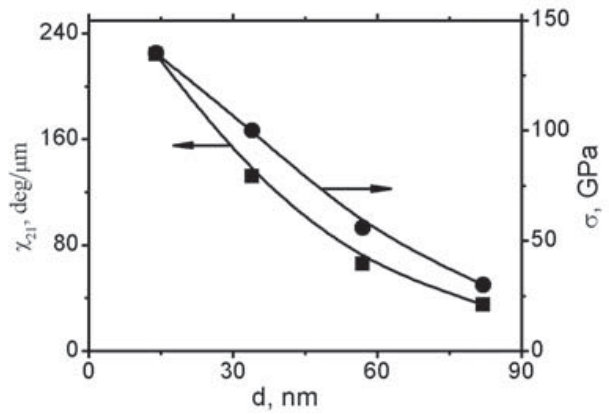

FIGURE 2. Internal stress dependence of the elastic curvature-torsion of the crystal lattice on the transverse grain size in the coating layer on the basis of $\mathrm{Zr}-\mathrm{Y}-\mathrm{O}$

At the same time, depending on the distance between the interphase boundaries, the greatest values of the internal elastic stress and the curvature-torsion of the crystal lattice in the coating are typical for the stage of the layer formation, i.e. at the distance of 400-500 nm from the interface between the layers (Fig. 2). Then both values gradually decrease in the direction of the interphase boundary.

\section{CONCLUSION}

The layers on the basis of $\mathrm{Zr}-\mathrm{Y}-\mathrm{O}$ in the $\mathrm{Zr}-\mathrm{Y}-\mathrm{O} / \mathrm{Si}-\mathrm{Al}-\mathrm{N}$ multilayer coating have a columnar structure. The grain size of the column cross-section is $80 \mathrm{~nm}$; the height of the column is about $1000 \mathrm{~nm}$. In this case, its value corresponds to the thickness of the deposited layer.

The structure of all the $\mathrm{Zr}-\mathrm{Y}-\mathrm{O}$ layers in the multilayer coating is not dependent on the position of the coating layer.

The curvature-torsion of the crystal lattice and the internal elastic stresses depend on the grain cross-section size of the $\mathrm{Zr}-\mathrm{Y}-\mathrm{O}$ layer. The larger the grain cross-section size in the layer, the smaller the curvature-torsion of the crystalline lattice and the internal elastic stresses. Such dependences are caused by the structure of the nanograins formed in the coating.

The work was supported in the scope of basic scientific research of the state academies of sciences for 20132020 performed within the scope of state task "Science NRTPU".

\section{REFERENCES}

1. E. V. Kozlov, N. A. Koneva, A. N. Zhdanov, N. A. Popova, and Yu. F. Ivanov, Fiz. Mezomekh. 7(4), 93 (2004).

2. P. A. Langjahr, R. Oberacker, and M. J. Hoffmann, J. Am. Ceram. Soc. 84, 1301 (2001).

3. X. Huang, A. Zakurdaev, and D. Wang, J. Mater. Sci. 43, 2631 (2008).

4. J. Zhiqiang, J. A. Haynes, and E. Voelk1, J. Am. Ceram. Soc. 84, 929-36 (2001).

5. V. P. Sergeev, V. E. Panin, R. N. Rizakhanov, A. S. Koroteev, M. V. Fedorischeva, V. V. Neufeld, AND M. P. Kalashnikov, Adv. Mater. Res. 880, 146 (2014).

5. V. P. Sergeev, V. P. Yanovsky, Yu. N. Paraev, S. A. Kozlov, and S. A. Zhuravlyov, Fiz. Mezomekh. 7(Spec. Iss.), 333 (2004).

6. M. V. Fedorischeva, V. P. Sergeev, N. A. Popova, and E. V. Kozlov, Mater. Sci. Eng. A 483-484, 644 (2008).

7. A. N. Tyumentsev, A. D. Korotaev, and Yu. P. Pinzhin, Phys. Mesomech. 7(3-4), 31 (2004).

8. N. A. Koneva, N. A. Popova, and E.V. Kozlov, Mater. Sci. Forum, 633-634, 605 (2010).

9. V. E. Panin, Phys. Mesomech. 16(3) (2013).

10. A. D. Korotaev, D. P. Borisov, V. Yu. Moshkov, S. V. Ovchinnikov, Yu. P. Pinzhin, and A. N. Tyumentsev, Phys. Mesomech. 12(5-6), 269 (2009).

11. M. V. Fedorischeva, V. P. Sergeev, A. R. Sungatulin, O. V. Sergeev, N. A. Popova, L. L. Nikonenko, M. P. Kalashnikov, and E. V. Kozlov, Bull. Russ. Acad. Sci. Phys. 75(12), 1683 (2011).

12. R. Daniel, K. J. Martinschitz, J. Keckesm and B. C. Mitterer, Acta Mater. 58, 2621 (2010).

13. E. V. Kozlov, A. N. Zhdanov, and N. A. Koneva, Phys. Mesomech. 9(3-4), 75 (2006).

14. E. V. Kozlov, N. A Koneva, L. I. Trishkina, A. N. Zhdanov, and M. V. Fedorischeva, Mater. Sci. Forum 584586, 35 (2008). 